\title{
炭材内装法による亜鉛製錬残渣からの脱亜鉛・溶融挙動
}

杉山岳文 ${ }^{* 1}$, 大中一德 ${ }^{* 1}$, 松井宏司 ${ }^{* 2}$

\section{A Fundamental Investigation about Direct Reduction Phenomena Using Carbon Composite Pellets for Zn Reaching Residue}

\author{
Takefumi Sugiyama, Kazunori Onaka, and Hiroshi Matsui
}

\section{Synopsis}

A direct reduction process using carbon composite pellets is now received much attention because of the ability to recycle various metallic wastes. Some features of direct reduction using carbon composite pellets for Zn reaching residue are shown by the labo-scale experiments in this paper. High removal performance for Zn from wastes and melting behavior below $1573 \mathrm{~K}$ was identified.

\section{1. 緒言}

炭材内装法による各種金属酸化物の還元法は従来より 盛んに研究されており，MIDREX 法 , HYL- III法等に代表 される天然ガスを利用した還元法に比べて，一般的に還元 時間が極めて短いことを特徵の一つとする ${ }^{1)}$. 本法を利用 したプロセスとして，回転床炉を用いた INMETCO 法， FASTMET 法が共に実用化されており，INMETCO 法にお いてはすでに 1978 年から米国 INMETCO 社において操業 が開始されている2).

炭材内装法による還元法は粉鉱石からの直接還元鉄製 造のみならず，ダスト，スケールなど鉄系廃棄物の処理に 対しても有望視されており，全世界的に環境問題がクロー ズアップされている近年, 本法の金属リサイクル能力に対 し改めて注目が高まっている.この方法は鉄系以外の廃棄 物，例えば亜鉛の精錬残渣の処理，に対しても有効である と考えられる.しかしながら，これら鉄系廃棄物以外の処 理についての報告はまだ多くはなされていない，乥こで本 報では, 炭材内装法による非鉄系廃棄物の処理として, 回 転床炉を利用する INMETCO 法のプロセスを念頭におき， 亜鉛浸出残渣からの脱亜鉛および溶融挙動について基礎 実験を行ったので炎の結果について報告する．

\section{2 . 亜鉛浸出残渣}

亜鉛の湿式製錬法では，硫化鉱を主体とした鉱石を選 鉱, 焙焼して $\mathrm{ZnO}$ とした後, $\mathrm{H}_{2} \mathrm{SO}_{4}$ 溶液で浸出し, 得ら れた $\mathrm{ZnSO}_{4}$ 溶液から電解採取によって金属亜鉛を得る上 記浸出工程では, 鉱石中の $\mathrm{Fe}$ を起因として希 $\mathrm{H}_{2} \mathrm{SO}_{4}$ 溶液 に難溶性の $\mathrm{ZnO} \cdot \mathrm{Fe}_{2} \mathrm{O}_{3}$ が生成し，残渣の一部となる.残 渣からの亜鉛回収法として , スラグ・フォーミング法やウ エルツ法, 硫酸化焙焼法などが知られている ${ }^{3)}$.

\section{3 . 炭材内装法による還元プロセス}

微粒状の金属酸化物と微粉炭やコークスブリーズなど の還元材を混合・造粒した後, 加熱することによって金属 酸化物の還元を行うプロセスには, 加熱炉としてロータ リーキルンを用いる方法と回転床炉を用いる方法があり， INMETCO 法は後者に属する．

Fig.1に INMETCO 法の主要設備となる回転床炉の概念 図を示す ${ }^{4)}$.混合造粒後の生ペレットは炉内に装入された 後, 回転する炉床に載って移動し, 1 回転する間にバーナ， 雾囲気，炉壁からの輻射によって急速に加熱還元される． 還元後のペレットは水冷スクリューによって炉外へと排 出される.一般的に, 回転床炉法はロータリーキルン法に 
比べて炉内での造粒物の割れや欠けが少なく微粉が発生 し難く，金属化率の高い焼成ペレットが得られるといった 利点を有する .この方法により，亜鉛残渣の還元が可能で あることの確認と, 温度, 雰囲気, 時間, 炭材添加量な ど，光の最適処理条件を把握するために，小型実験炉を用 いた基礎調査を行なった・また，残渣中に共存する酸化鉄 の影響も調査した .

\section{4 . 実験方法}

\section{1 実験装置}

実験装置として Fig.2 に示す抵抗加熱式加熱炉を用い た . $100 \mathrm{~V} / 6.5 \mathrm{~kW}$ の電源を用い, アルミナ製の管状耐火物 の外面に取り付けられたシリコニット発熱体を通電加熱 することによって，管内の均熱帯部分を $1673 \mathrm{~K}$ まで加熱 することが可能である .炉内の雰囲気ガス成分を調整する ため，管の両端に SUS 製の治具を装着して外気の進入を 防止した .またガス採取管によって試料近傍からガスを吸 引し，ガス中の各成分を連続的に分析した . $\mathrm{CO}, \mathrm{CO}_{2}$ 濃 度は赤外線吸収式, $\mathrm{O}_{2}$ 濃度はジルコニア式のセンサによっ て分析した。

\section{2 耐爆裂性評価実験}

回転床炉法を念頭においた場合，造粒物は，炉内への装 入に伴い室温付近から $1373 \sim 1573 \mathrm{~K}$ 程度まで急激に加熱 されるため，爆裂，粉化する懸念がある. 爆裂，粉化は回 転床炉の操業を困難にするため, 造粒物の耐爆裂性を調査 した。

\section{2 .1 供試材}

Table 1 に示す成分の亜鉛浸出残渣と Table 2 に示す成分 のコークス粉を混合し，造粒を促進するため水を添加した 後，押出し式の造粒機を用いて直径 : 約 $10 \mathrm{~mm}$ ，長さ：約 10mm の円柱状に造粒した . 造粒後, 393K の乾燥炉内に 所定の時間保持することによって造粒物の含水率を調整 し, 供試材とした .

\subsection{2 急速加熱の手法}

回転床炉法と同樣の急速加熱をシュミレートするため， 以下の手順で行った .炉内と同一温度になるまでアルミナ 製の小容器を炉内で予熱した後,小容器に造粒物を並べて 再度炉内人装入し, 3 分間保持した後, 造粒物を取り出し た.爆裂の有無は外観を目視で観察して判断した.実験条 件をTable 3 に示す .

\section{3 還元実験}

\section{3 .1 供試材}

4.2 .1 節と同樣の手法によって成形した造粒物を，乾
燥炉にて 393K，2 時間加熱乾燥して無視できる濃度まで 水分を除去し，供試材とした . 乾燥後の成分をTable 4 に 示す。

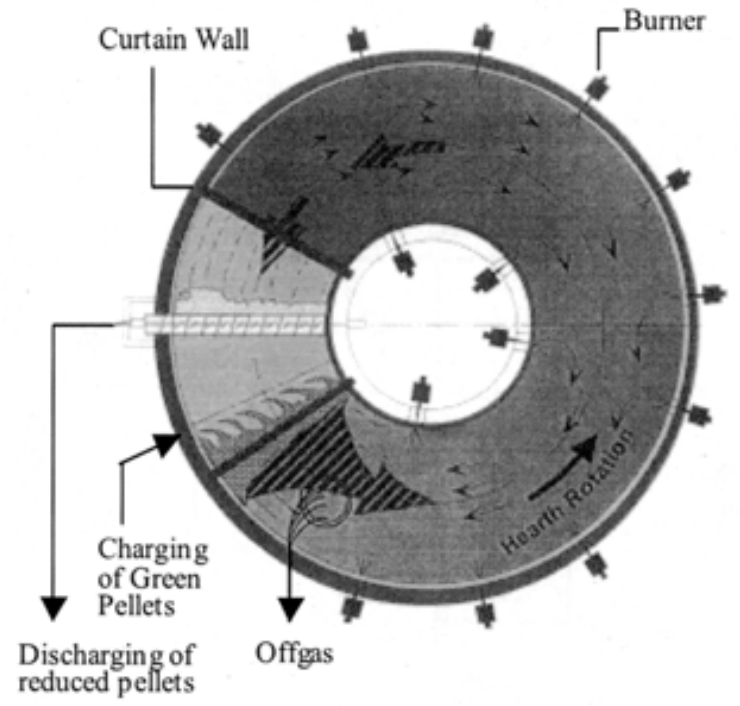

Fig.1. Schematic of INMETCO rotary hearth furnace.

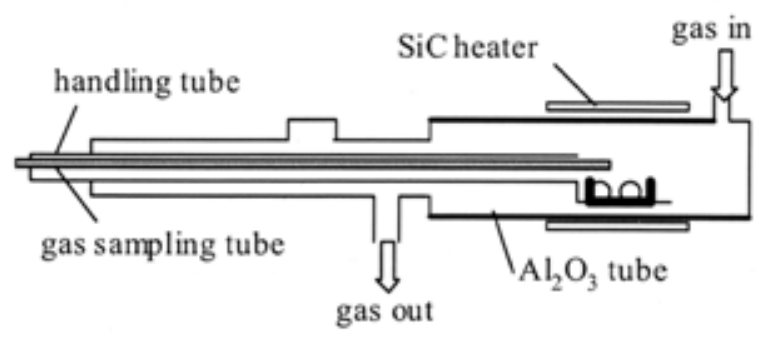

Fig.2. Schematic of experimental apparatus.

Table 1. Chemical compositions of reaching residue(mass \%).

\begin{tabular}{c|c|c|c|c}
\hline Total Fe. & Metallic Fe. & $\mathrm{Zn}$ & $\mathrm{SiO}_{2}$ & $\mathrm{~Pb}$ \\
\hline $25 \sim 35$ & $0 \sim 1$ & $20 \sim 30$ & $5 \sim 10$ & $3 \sim 10$ \\
\hline
\end{tabular}

Table 2. Compositions of carbon sources(mass\%).

\begin{tabular}{c|c|c}
\hline F.C. & V.M. & Ash \\
\hline $85 \sim 90$ & $1 \sim 2$ & $10 \sim 12$ \\
\hline
\end{tabular}

Table 3. Experimental conditions for burst test.

\begin{tabular}{c|c}
\hline water content of samples & $0 \sim 15$ mass $\%$ \\
\hline Furnace temp. & $1273 \sim 1473 \mathrm{~K}$ \\
\hline Heating time & $3 \mathrm{~min}$ \\
\hline Gas composition & $\mathrm{N}_{2}$ \\
\hline
\end{tabular}

Table 4. Chemical compositions of samples for reduction test(mass\%).

\begin{tabular}{c|c|c|c|c}
\hline $\mathrm{C}$ & T.Fe. & $\mathrm{Zn}$ & $\mathrm{SiO}_{2}$ & $\mathrm{~Pb}$ \\
\hline $10 \sim 25$ & $20 \sim 30$ & $15 \sim 20$ & $3 \sim 8$ & $2 \sim 4$ \\
\hline
\end{tabular}




\section{3 .2 加熱還元実験}

所定濃度に調整したガスを炉内へ導入した後 , 数個の造 粒物を，炉内にて予熱されたアルミナ製の小容器に単層と なるように並へて炉内へと装入した．加熱条件を Table 5 に示す.なお，加熱温度は試料装入前に $\mathrm{R}$ 型熱電対によっ て測定した炉内温度であり，酸素濃度は導入ガスの濃度で ある.試料は加熱後直ちに炉内から取り出し, 不活性雾囲 気下で室温付近まで泠却した 。

Table 5. Experimental conditions for reduction test.

\begin{tabular}{c|c}
\hline Furnace temp. & $1423 \sim 1573 \mathrm{~K}$ \\
\hline Heating time & $10 / 15 / 20 \mathrm{~min}$ \\
\hline Gas composition & $\mathrm{N}_{2} / \mathrm{N}_{2}+\mathrm{O}_{2}$ \\
\hline
\end{tabular}

\section{5 . 結果および考察}

\section{1 而爆裂性評価実験}

Fig.3 に結果を，Fig.4 に爆裂前後の試料の外観を示す． 今回の実験条件では, 試料装入時の炉内温度が高く,造粒 物の含水率が高い条件で爆裂が認められ，炉内温度 $1473 \mathrm{~K}$ では, 含水率が $3 \mathrm{wt} \%$ 以上の全ての試料において爆裂か認 められた 温度が高くかつ含水率が高いものにおいて爆裂 が発生している事から,水分の急激かつ多量の蒸気化によ り爆裂が発生したものと考えられる。

\section{2 還元実験}

\section{2 .1 炉内温度と保持時間の影響}

室素雾囲気下で加熱した場合の残留亜鉛濃度および脱 亜鉛率に及ぼす炉内温度，炉内保持時間の影響を Fig.5， Fig.6 に示す .なお，脱亜鉛に伴う試料の減量を考慮し， 重量変化の無視できる鉄濃度を用いて加熱後の亜鉛濃度 を補正して，脱亜鉛率は式(1)で定義した .

$\eta_{Z n}=\left(T . Z n^{0}-T . Z n^{1} \times T . F e^{0} / T . F e^{1}\right) / T . Z n^{0} \times 100 \cdots(1)$ ここで ,

$\eta_{Z n}:$ 脱亜鉛率 $[\%]$

$T . Z n^{0}:$ 加熱前の亜鉛濃度 [mass\%]

$T . Z n^{1}:$ 加熱後の亜鉛濃度 [mass\%]

$T . F e^{0}:$ 加熱前の鉄濃度 [mass\%]

$T . F e^{1}:$ 加熱後の鉄濃度 [mass\%]

炉内温度が高いほど，短時間で高い脱亜鉛率を示し $1473 \mathrm{~K}$ 以上では 10 分間の保持時間で脱亜鉛率は $95 \%$ 以上， 残留亜鉛濃度は $1.5 \%$ 以下に低下した . Fig.7 に, 同一試料 における酸化鉄の還元挙動を示す．なお，加熱前の M-Fe は無視できる濃度のため 鉄金属化率は式 (2)で定義した .

$\eta_{\mathrm{Fe}}=M . F e^{1} / T . F e^{1} \times 100 \cdots \cdots \cdots \cdots \cdots \cdots \cdots \cdots(2)$ ここで，

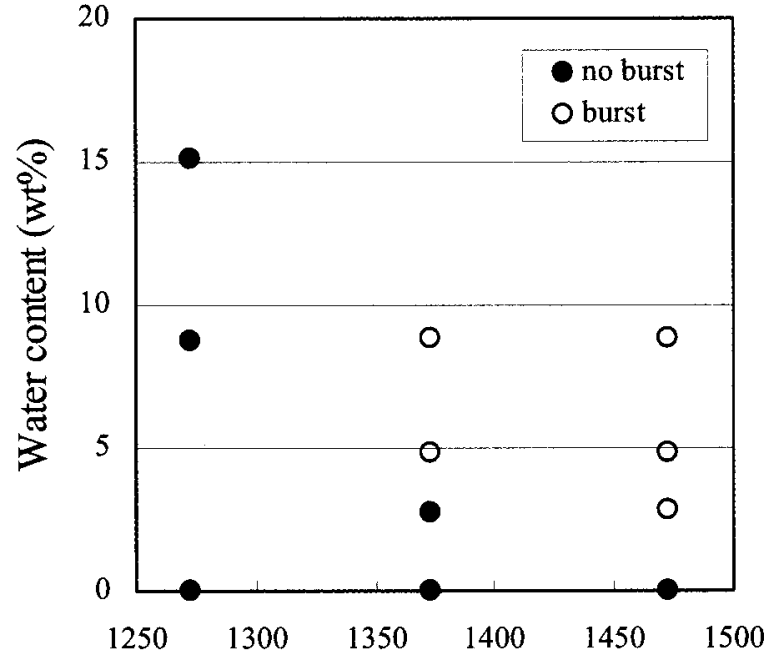

Furnace temperature $(\mathrm{K})$

Fig.3. Effects of furnace temperature and water content on bursting of samples.

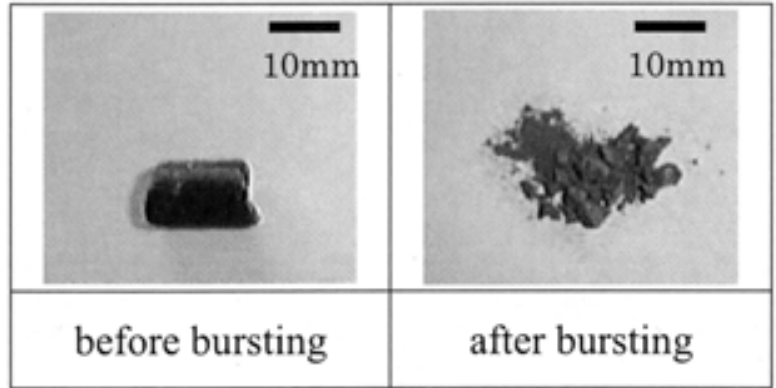

Fig.4. Shape of samples before and after heating.

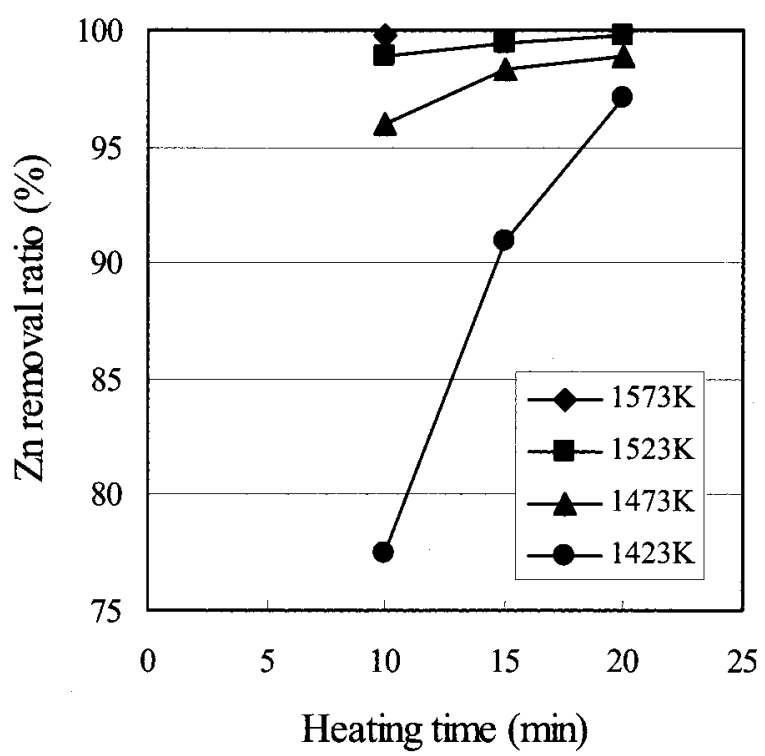

Fig.5. Effects of furnace temperature and heating time on the $\mathrm{Zn}$ removal ratio. 


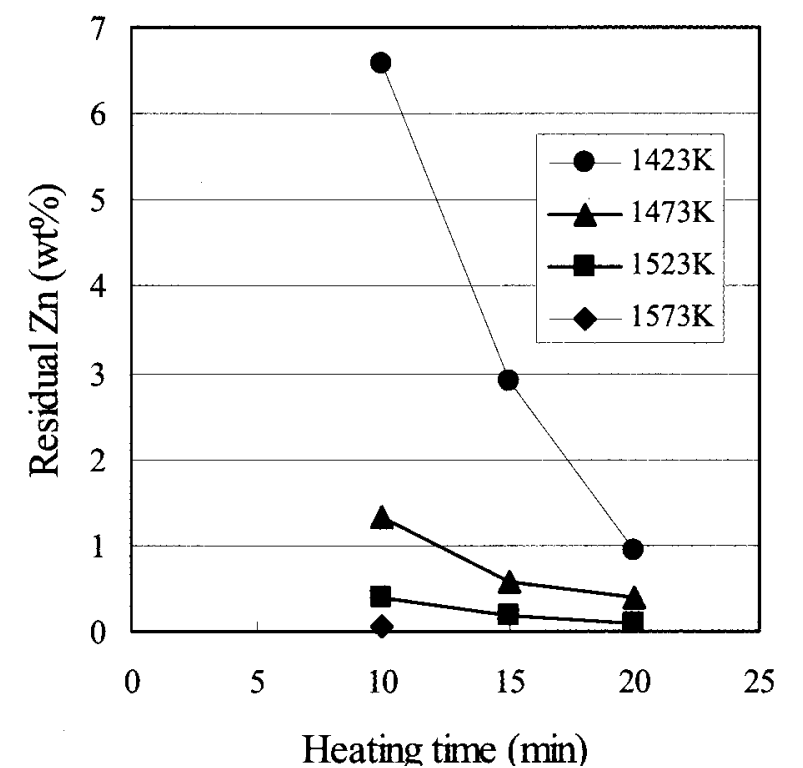

Fig.6. Effects of furnace temperature and heating time on residual $\mathrm{Zn}$.

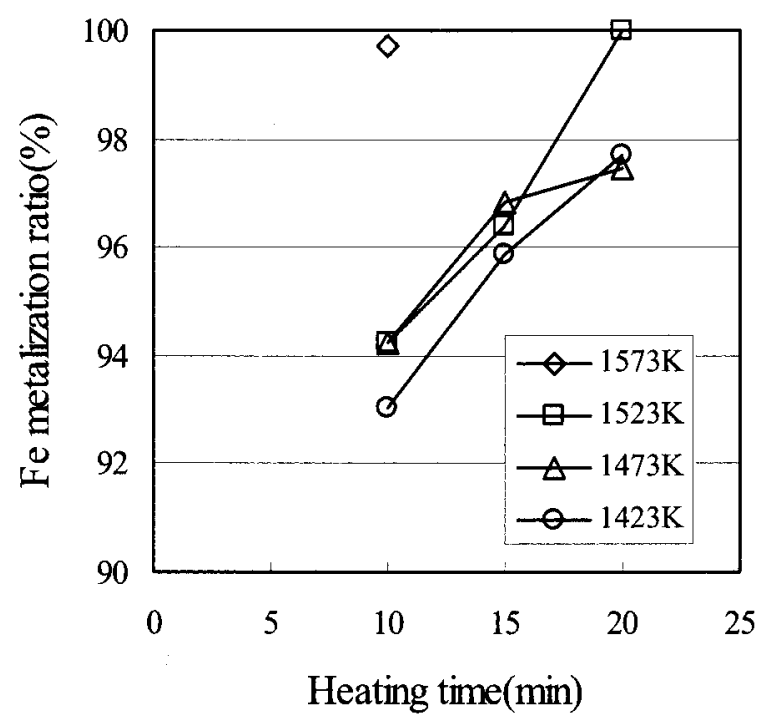

Fig.7. Effects of furnace temperature on Fe-metalization degree.

$\eta_{\mathrm{Fe}}:$ 鉄金属化率 [\%]

$M . F e^{1}:$ 加熱後の金属鉄濃度 [mass\%]

今回の実験条件では，炉温が高く，保持時間が長いほど 鉄金属化率が高くなる傾向か認められ，最終的には $96 \%$ を超える極めて高い金属化率を達成できた．

Fig.8 に 10 分間加熱した後の試料外観を示す.温度の上 昇に伴い表面に微細なひび割れが発生しているが，欠損や 粉化はなかった .

\section{2 .2 カーボン含有量の影響}

Fig.9 に窒素雰囲気，1473K の炉内で加熱した場合の脱 亜鉛率に及ぼすカーボン含有量の影響を示す.なおカーボ

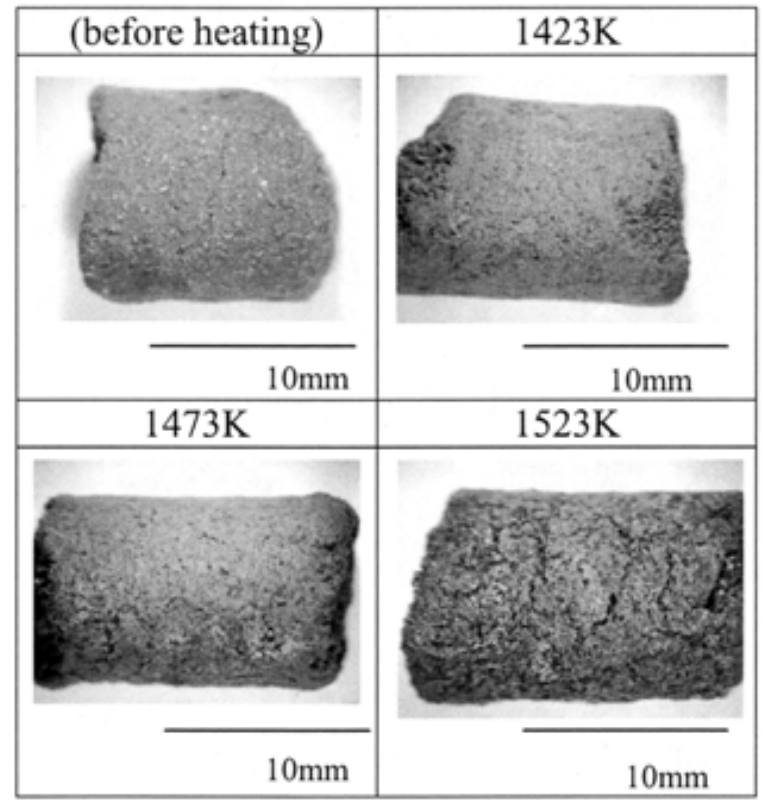

Fig.8. Samples before and after reduction.

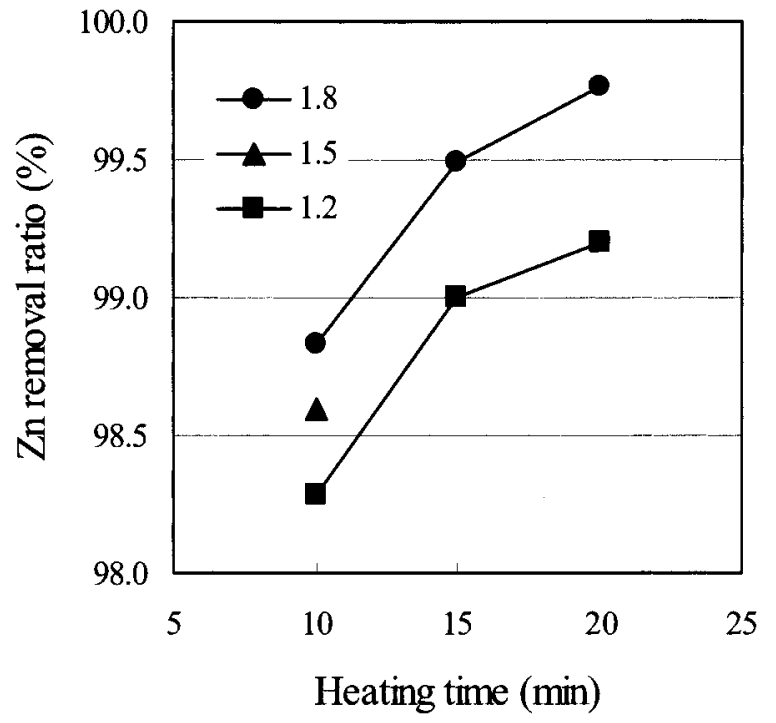

Fig.9. Effects of $C$ content on de-Zn degree.

ン含有量は酸化鉄, 酸化亜鉛, 酸化鉛に対する還元当量の 倍数で示した.いずれも還元当量を超えてカーボンを添加 したが, カーボン含有量が高いほど, 短時間で高脱亜鉛率 に達した。

以上のような亜鉛浸出残渣の還元, 脱亜鉛挙動に及ぼす 温度, カーボン含有量の影響は, 炭材内装法による酸化鉄 の還元挙動 ${ }^{5)}$ に類似しており，同樣にコークスのガス化 反応が還元反応の律速過程となっていると考えられる.

5.2 .3 加熱雰囲気の影響

$1523 \mathrm{~K}$ の炉内で 10 分間保持した場合の脱亜鉛挙動に及 
ぼす酸素濃度の影響を Fig.10 に , 鉄金属化率に及ぼす影 響を Fig.11 示す . ガス中の酸素濃度の増加に伴い脱亜鉛 率は低下したが, 本実験条件下ではいずれも $97 \%$ 以上と 高い脱亜鉛率であった 一方鉄金属化率は通気ガス中の酸 素濃度の増加に伴い急激に低下した。

Fig.12に, 加熱後の試料の外観を示す.酸素濃度が $0.8 \mathrm{vol} \%$ では試料は溶融しなかったが, $1.5 \mathrm{vol} \%$ では試料の 底部がアルミナ製容器と溶着した .酸素濃度が $5.7 \mathrm{vol} \%$ で は, 容器内に溶融物が沈積していた . 炭材内装法における 酸化鉄還元時の溶融現象 ${ }^{6)}$ に比して, 本実験での溶融現 象は低温で起き,また試料内部の空洞も観察されなかった ので，異なる原因で溶融が起きているものと推定される．

上記の試料の溶融は，回転床炉においては被加熱物の排 出・付着層の堆積 , ロータリーキルンではキルンリングの 形成など光の操業に悪影響を及ぼすため，以下に光の原因 を考察した。

一般に亜鉛の還元揮発製錬においては，(3) 式によって 生成した CO ガスによって (4) 式の還元反応が起き, 高温 下においてガス状の亜鉛が揮発するものとされる.また同 時に鉱石中の酸化鉄は (5) 式,(6) 式を経て金属鉄へと還元 されることが知られている ${ }^{3)}$.

$$
\begin{aligned}
& \mathrm{C}(\mathrm{s})+\mathrm{CO}_{2}(g)=2 \mathrm{CO}(\mathrm{g}) \cdots \cdots \cdots \cdots \cdots \cdots \cdots \cdots \cdots \cdots(3) \\
& \Delta G^{0}=170460-174.43 \times T[\mathrm{~J}] \\
& \mathrm{ZnO}(\mathrm{s})+\mathrm{CO}(\mathrm{g})=\mathrm{Zn}(\mathrm{g})+\mathrm{CO}_{2}(g) \cdots \\
& \Delta \mathrm{G}^{0}=178020-111.67 \times \mathrm{T}[\mathrm{J}] \\
& \mathrm{Fe}_{3} \mathrm{O}_{4}(\mathrm{a})+\mathrm{CO}(\mathrm{g})=3 \mathrm{FeO}(\mathrm{s})+\mathrm{CO}_{2}(\mathrm{~g}) \cdots \cdots \cdots \cdots \cdot(5) \\
& \Delta G^{0}=45110-55.00 \times T[\mathrm{~J}] \\
& \mathrm{FeO}(s)+\mathrm{CO}(g)=\mathrm{Fe}(Y)+\mathrm{CO}_{2}(g) \\
& \Delta G^{0}=-17990+21.92 \times T[\mathrm{~J}]
\end{aligned}
$$

上記熱力学データを用いて作図した $\mathrm{ZnO}, \mathrm{Fe}_{\mathrm{t}} \mathrm{O}$ の炭素 還元平衡図を Fig.13 に示す . 図中には , 試料近傍にて測 定した $\mathrm{CO} / \mathrm{CO}_{2}$ 比の推移をプロットした．導入ガスの酸素 濃度が高い方が 加熱中に測定した $\mathrm{CO} / \mathrm{CO}_{2}$ 比が低かった .

Table 6 に酸素濃度 $5.7 \mathrm{vol} \%$ にて加熱還元して得られた 試料成分を示す.試料には鉄分の他に残渣起因の $\mathrm{SiO}_{2}$ が 存在している．この成分組成においては， $\mathrm{FeO}-\mathrm{SiO}_{2}$ 系 状態図 ${ }^{7)}$ より， $\mathrm{SiO}_{2}$ の存在によって融点が $1473 \mathrm{~K}$ 程度の 低融点スラグが生成し得ることがわかる .

したがって , 導入ガスの酸素濃度の増加に伴って還元能 力が低下した結果, 高温領域まで残存する酸化鉄相が増加 し，残渣中の $\mathrm{SiO}_{2}$ との反応による低融点相を形成するこ とによって, ペレットが溶融し易くなるものと考えられ る .

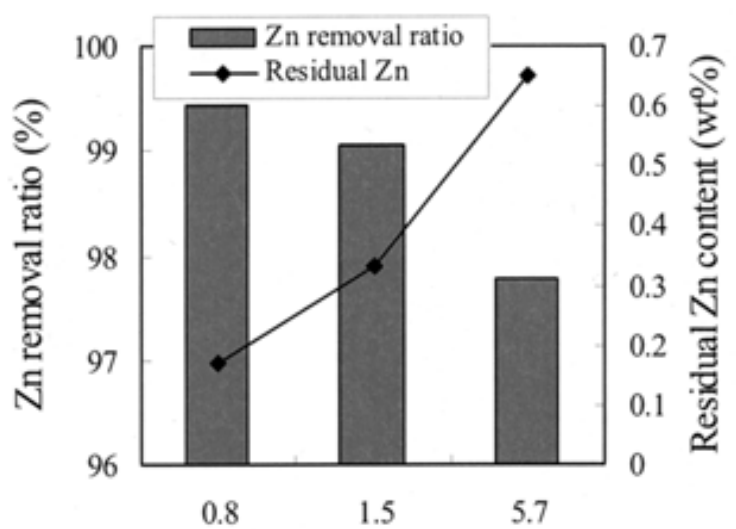

Oxygen content of input gas (vol\%)

Fig.10. Effect of oxygen content of origin gas on de-Zn.

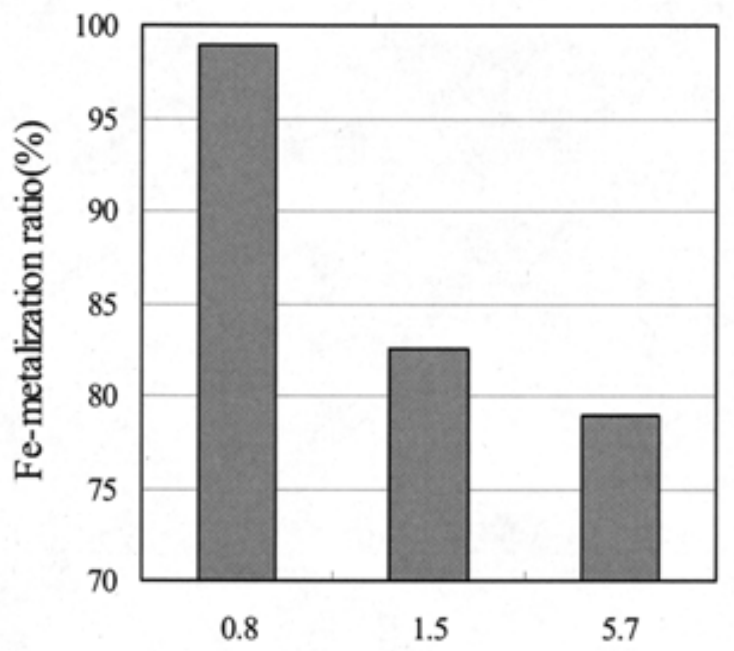

Oxygen content of input gas(vol\%)

Fig.11. Effect of oxygen content of origin gas on Fe-metalization.

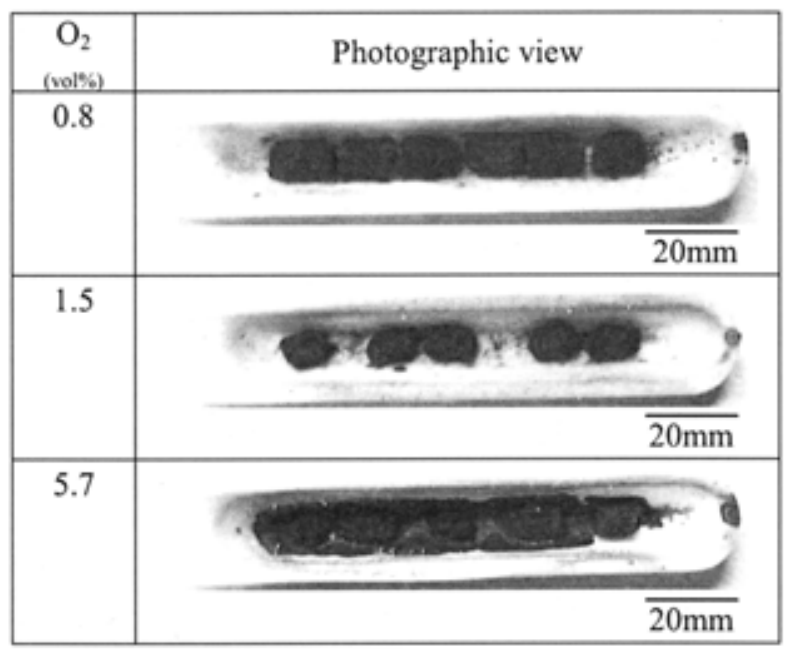

Fig.12. Photographic view of samples after heating. 


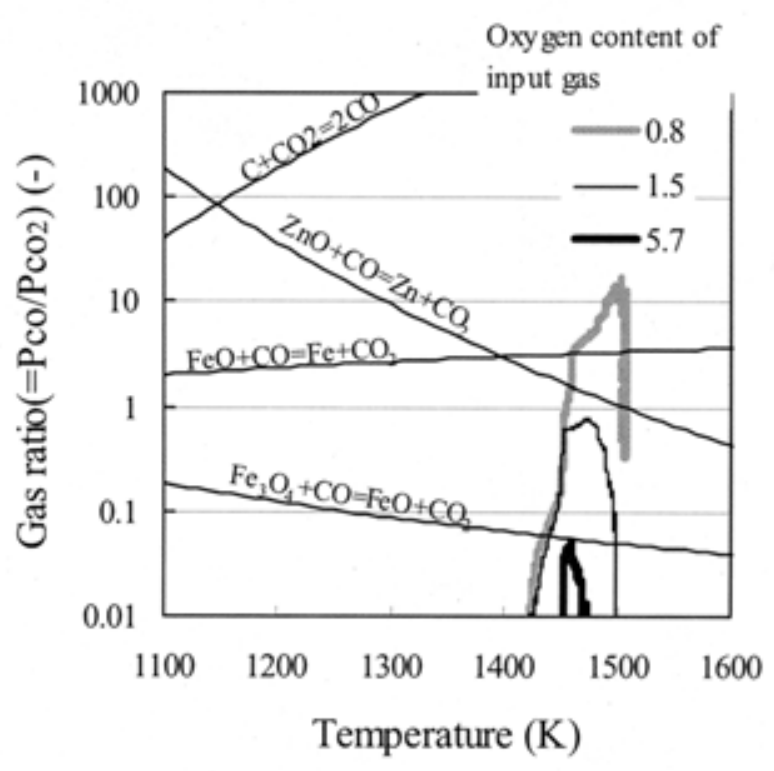

Fig.13. Fe-Zn-C reduction equillibrium diagram and $\mathrm{CO}_{2} / \mathrm{CO}$ during heating.

Table 6. Chemical compositions of samples after reduction test (mass\%).

\begin{tabular}{c|c|c|c|c|c}
\hline $\mathrm{C}$ & $\mathrm{T} . \mathrm{Fe}$. & $\mathrm{FeO}$ & $\mathrm{Zn}$ & $\mathrm{SiO}_{2}$ & $\mathrm{~Pb}$ \\
\hline $0 \sim 3$ & $40 \sim 50$ & $9 \sim 12$ & $0.5 \sim 1$ & $10 \sim 15$ & $<0.1$ \\
\hline
\end{tabular}

\section{6 ．結 言}

亜鉛浸出残渣に対する炭材内装法の適用について，実験 室規模の抵抗加熱式加熱炉を用いて基礎調査を行った結 果 , 以下の結論を得た .

(1) 造粒物の炉内への装入に際し，炉内温度が高く，造粒 物の含水率が高い場合に爆裂した，爆裂の抑止のためには 含水率の低減が必要であった .

（2）炉内温度を高め，カーボン含有量を増加することに よって , 脱亜鉛速度を高めることができ, 脱亜鉛率は最大 で99\%に達した。

(3) 供給ガス中の酸素濃度の増加に伴い, 脱亜鉛能力の低 下のみならず,試料の溶融が引き起こされた .脱亜鉛速度 向上のため, 高い炉内温度で処理する場合，同時に雰囲気 中の酸素濃度の低減が必要といえる。

\section{(文 献)}

1)森広司:西山記念技術講座 ,165(1997), 117.

2)J.K.Pargeter ,R.H.Hanewald and D.E.Dombrowski:

Conservation \& Recycling ,8(1985) ,363.

3)阿座上竹四: 非鉄金属精錬，矢沢涁編 講座·現代の金属

学 製錬編 2 ,日本金属学会, (1980), 107.
4)広中博美，山本義靖、関原英男: 電気製鋼, 71(2000), 103.

5)張興和, 高橋礼二郎，八木順一郎:鉄と鋼,81(1995), 1043.

6)松村俊秀，竹中芳通，清水正賢，根上卓也，小林勲，浦上 昭:鉄と鋼，84(1998）,405.

7)J.F.Elliott ,M.Gleiser and V.Ramakrishna:Thermochemistry for Steelmaking Vol. II ,Addison-Wesley Pub. Co. ,(1963). 